\title{
PREDICTION OF GRAVITY ANOMALIES FOR GEOPHYSICAL EXPLORATION
}

\author{
T. O. Idowu \\ Department of Surveying and Geo-informatics, Federal University of Technology, \\ Yola. E-mail: timbetty2000@yahoo.com
}

\begin{abstract}
Interpretation of gravity anomalies (determined on the earth's surface) reveals information on mineral resources beneath the earth. The density of gravity stations (where gravity anomalies are determined) is critical to the successful interpretation of these anomalies. Where the density of the available gravity anomalies is not enough, for a particular purpose of geophysical exploration, more gravity stations can be established within the surveyed area and the gravity anomalies observed for these stations. In some cases, where observations of gravity anomalies are not possible due, probably, to inaccessibility of the newly chosen gravity stations, the required gravity anomalies for such stations can be estimated (predicted). Currently, classical least squares technique is used to accomplish such task. However, the technique does not produce optimum results because its formulation assumes that the observed gravity anomalies, used for the prediction, are error free, whereas, all observed quantities are affected by random errors. Therefore, in this study, an attempt is made to carry out prediction of gravity anomalies for geophysical exploration using least squares collocation technique. This is considered to be a better alternative because its formulation takes the presence of random errors of observations in the observed quantities into consideration and makes provision for filtering out these errors while predicting the signals of interest at the required number of stations.
\end{abstract}

\section{INTRODUCTION}

The search for mineral resources represents the major geophysical exploration activity in the world today. This is because mineral resources are the concealed subsurface geological features of most economic interest to many countries of the world.

Mineral resources can be described as beneficial subsurface features whose natural habitat is the earth. They include solid metallic minerals such as, iron ore, zinc etc, solid non-metallic minerals like limestone, marble etc., liquid minerals such as oil, water etc., and gaseous minerals like gasses in buried cavity. Mineral exploration has been in existence for a long time. Its method, however, had been only drilling using percussion bits. This had posed a lot of risk as explorer could easily and ignorantly get exposed to dangerous materials underground. Also, it was uneconomical since decision as to where to drill was taken like a gamble because there was no prior information about the actual location of the concealed mineral before drilling. Later, in the early years of twentieth century, the continued efforts by explorers to look for more effective, less risky and more economical technique of sub-surface exploration led to the advent of geophysical exploration.

Geophysical exploration, defined by Reynolds (1998) as "making and interpreting measurements of physical properties of the earth to determine sub-surface conditions, usually with economic objectives such as discovery of mineral 
FUTY Journal of the Environment, Vol. I No.1, July 2006

(c) School of Environmental Sciences, Federal University of Technology, Yola - Nigeria.. ISSN 1597-8826

depositions", does not dispense with the need for drilling, but if properly applied, it can optimise exploration program by maximizing the rate of ground coverage and minimizing the drilling request. It is broadly divided into two methods: naturalsource and artificial-source methods. The natural-source methods are those making use of gravity and magnetic fields of the earth to search for local perturbation, in the natural fields, caused by the concealed geological features while the artificial-source methods involve propagation of artificial waves (e. g. seismic waves) through the earth interior which may be used analogously to natural-source method. Comparing the two methods, it was observed in Kearey and Brooks (1988) that the naturalsource method is logistically simpler to carryout than the artificial-source method. Also, in Senti (1988), the unit cost figures of different geophysical surveys carried out by the society of exploration geophysicists in 1987 were compiled to compare the two methods. The results showed that the natural-source method is more cost effective than the artificial-source method. Furthermore, it was reported in Gumert (1992) that the high speed of operation and current level of accuracy of gravity method led to better understanding of regional geology and economically limited the use of more expensive seismic survey for mineral exploration.

Generally, both natural-source and artificial-source methods are used for mineral exploration. However, in some countries such as Nigeria, only the seismic method is being used while the use of gravity method is rarely noticed. One of the reasons for this might not be unconnected with the inadequate gravity data in these countries. This necessitated the plan of Federal Government of Nigeria to set up Nigeria gravity network project committee (NGNPC) to establish various gravity networks of points in Nigeria for geodetic and geophysical studies. Unfortunately, due to inexplicable reasons, the aims of this committee have not been achieved to date (Osazuwa, 1995). Therefore, gravity values and hence gravity anomalies (obtained from gravity values) remain inadequate for geophysical exploration in Nigeria. Acquisition of gravity values for adequate gravity anomalies in these countries can be achieved by direct observation and/or mathematical estimation. Therefore, it is the objective of this paper to apply mathematical estimation technique, that is, least squares collocation technique for the prediction of gravity anomalies for geophysical exploration.

\section{METHODOLOGY}

The method used includes the application of least squares collocation technique for the prediction of gravity anomalies at the observation stations. The classical least squares technique, as discussed in Abdelrahman et al (1991), is also used to predict gravity anomalies at the same stations. This is for the purpose of comparison of the two techniques. Thereafter, the least squares collocation technique is used to predict gravity anomalies of other stations using the observed gravity anomalies of the observation stations.

\section{Data Acquisition}

The data used for the study, as abstracted from SNEPCO (1995), are shown in tables 1 and 2. Columns 1, 2, 3, 4 and 5 of table 1 give the station numbers, gravity anomalies $\left(\Delta \mathrm{g}_{\mathrm{i}}\right)$, $\mathrm{x}$-coordinates, $\mathrm{y}$-coordinates and gravity values $(\mathrm{g})$ of thirty gravity observation stations respectively. Columns 1,2, 3 and 4 of table 2 respectively show the station numbers, gravity anomalies, x-coordinates and y-coordinates of another fifteen gravity stations outside the observation stations whose gravity anomalies are predicted based on the observed gravity anomalies of table 1. 
Table 1: Data used for predicting gravity anomalies at observation stations

\begin{tabular}{|c|c|c|c|c|}
\hline Station number & $\Delta \mathrm{g}_{\mathrm{i}}(\mathrm{mGal})$ & $\mathrm{x}(\mathrm{m})$ & $\mathrm{y}(\mathrm{m})$ & $\mathrm{g}(\mathrm{mGal})$ \\
\hline 95D0301040 & -31.928500 & 692415.900 & 1189739.600 & 978061.4520 \\
\hline 95D0301060 & -31.772200 & 692604.800 & 1190200.600 & 978061.9706 \\
\hline 95D0301100 & -31.178600 & 692487.400 & 1191183.300 & 978066.1179 \\
\hline 95D0301120 & -30.773000 & 692408.200 & 1191676.600 & 978068.5372 \\
\hline 95D0301160 & -30.350500 & 692250.300 & 1192664.300 & 978071.3239 \\
\hline 95D0301200 & -29.833000 & 692092.800 & 1193652.000 & 978070.7214 \\
\hline 95D0301220 & -29.736200 & 692014.100 & 1194145.600 & 978070.3145 \\
\hline 95D0301260 & -29.421700 & 691855.600 & 1195133.000 & 978074.9719 \\
\hline 95D0301300 & -29.262800 & 691698.400 & 1196120.300 & 978079.2266 \\
\hline 95D0301318 & -29.038700 & 691627.000 & 1196564.400 & 978081.4502 \\
\hline 95D0301346 & -29.010000 & 691516.500 & 1197256.300 & 978084.2498 \\
\hline 95D0301381 & -28.987000 & 691378.700 & 1198120.300 & 978087.7926 \\
\hline 95D0301420 & -29.231300 & 691224.900 & 1199082.900 & 978087.7034 \\
\hline 95D0301460 & -29.609300 & 691066.600 & 1200069.900 & 978088.7919 \\
\hline 95D0301480 & -29.665300 & 690987.400 & 1200564.300 & 978090.4587 \\
\hline 95D0301500 & -29.897100 & 690908.300 & 1201058.100 & 978092.1069 \\
\hline $95 \mathrm{D} 0301540$ & -30.442700 & 690750.600 & 1202045.100 & 978092.7586 \\
\hline 95D0301580 & -30.579400 & 690593.200 & 1203032.800 & 978094.1567 \\
\hline 95D0301620 & -31.330000 & 690435.100 & 1204020.000 & 978092.1786 \\
\hline 95D0301638 & -31.223900 & 690364.100 & 1204463.600 & 978093.3157 \\
\hline 95D0301660 & -31.096500 & 690276.300 & 1205008.300 & 978096.8901 \\
\hline 95D0301700 & -30.958100 & 690119.500 & 1205994.800 & 978101.5534 \\
\hline 95D0301720 & -30.586200 & 690040.200 & 1206488.800 & 978103.2666 \\
\hline 95D0301740 & -30.112100 & 689961.600 & 1206982.400 & 978105.8462 \\
\hline 95D0301780 & -29.173300 & 689803.600 & 1207970.000 & 978109.4676 \\
\hline 95D0301800 & -28.809800 & 689724.300 & 1208464.300 & 978110.0709 \\
\hline 95D0301840 & -27.492100 & 689566.600 & 1209451.400 & 978113.7791 \\
\hline 95D0301860 & -26.900200 & 689488.000 & 1209945.000 & 978116.5442 \\
\hline 95D0301880 & -26.256800 & 689408.700 & 1210438.500 & 978118.1695 \\
\hline 95D0301920 & -25.579700 & 689251.400 & 1211426.300 & 978122.1145 \\
\hline
\end{tabular}


FUTY Journal of the Environment, Vol. 1 No.1, July 2006

(c) School of Environmental Sciences, Federal University of Technology, Yola - Nigeria.. ISSN 1597-8826

Table 2: Data for other gravity stations where gravity anomalies are predicted

\begin{tabular}{rlll}
\hline Station number & $\Delta \mathrm{g}_{\mathrm{i}}(\mathrm{mGal})$ & $\mathrm{x}(\mathrm{m})$ & $\mathrm{y}(\mathrm{m})$ \\
\hline 95D0301080 & -31.482100 & 692566.400 & 1190689.600 \\
95D0301140 & -30.585700 & 692329.100 & 1192170.900 \\
95D0301180 & -29.958800 & 692171.700 & 1193158.300 \\
95D0301240 & -29.578400 & 691934.100 & 1194638.800 \\
95D0301280 & -29.177600 & 691777.100 & 1195626.900 \\
95D0301334 & -29.024300 & 691563.900 & 1196959.900 \\
95D0301360 & -29.070900 & 691461.000 & 1197601.900 \\
95D0301400 & -29.197900 & 691303.800 & 1198588.800 \\
95D0301440 & -29.462800 & 691145.300 & 1199576.600 \\
95D0301520 & -30.141500 & 690829.600 & 1201551.600 \\
95D0301560 & -30.588100 & 690672.000 & 1202538.800 \\
95D0301600 & -30.817100 & 690514.000 & 1203526.600 \\
95D0301680 & -31.218200 & 690199.000 & 1205500.900 \\
95D0301760 & -29.729900 & 689882.800 & 1207475.900 \\
95D0301820 & -28.225200 & 689645.300 & 1208957.800 \\
\hline
\end{tabular}

\section{Least Squares Collocation Technique}

Least squares collocation is an advanced least squares method. Schwarz (1976a) used it for the adjustment of a large geodetic network. Rapp (1986) applied it in the prediction of geoidal undulations and components of deflection of verticals. In Ezeigbo (1988), it was described as an appropriate method and a better alternative than other methods in handling gravity depended observations. Its concept combines least squares adjustment to obtain parameters (X), least squares filtering of error (V) and least squares prediction of signals (S) using observed quantities (l). As in Rapp (1986), the ultimate generalization and the minimum principle of the linear least squares collocation model are respectively given as (1) and (2).

$$
\begin{aligned}
& l=A X+S+V \\
& S^{T} C_{s l} S+V^{T} C_{V V}^{-1} V=\min \text { imum }
\end{aligned}
$$

Where: $C_{s l}=$ Covariance function between observations and signals

$\mathrm{C}_{\mathrm{vv}}=$ Covariance matrix of the observations

$$
A=\partial l / \partial X
$$

The superscript $\mathrm{T}$ indicates the transpose of a vector and/or matrix.

Its theory and detailed proof of equations are fully discussed in Moritz (1972), Moritz (1978), Krakiwsky (1975), Rapp (1986) and Ayeni (2001). However, for easy reference, the step by step applications of the equations are stated here.

$$
\begin{aligned}
S & =C_{s l} C_{l l}^{-1}(l-A X) \\
X & =\left(A^{T} C_{l l}^{-1} A\right)^{-1} A^{T} C_{l l}^{-1} l \\
V & =C_{V V} C_{l l}^{-1}(l-A X)
\end{aligned}
$$

Where: $C_{l l}=C_{s l}+C_{V V}$ (Covariance function between observations). 
FUTY Journal of the Environment, Vol. I No.1, July 2006

(c) School of Environmental Sciences, Federal University of Technology, Yola - Nigeria.. ISSN 1597-8826

Other notations used are:

$$
\begin{aligned}
\sigma_{0}^{2} & =1 \quad \text { (a-priori variance of unit weight) } \\
C_{X X} & =\left(V^{T} C_{l l}^{-1} V\right)\left(A^{T} C_{l l}^{-1} A\right)^{-1} /(n-m) \quad \text { (error covariance matrix of parameters) } \\
C_{-s s}^{C} & =C_{s s}-C_{s l} C_{l l}^{-1} C_{s l}^{T}+H A C_{X X} A^{T} H^{T} \quad \text { (error covariance matrix of signals) } \\
H & =C_{s l} C_{l l}^{-1}
\end{aligned}
$$

For $A=0$, (1) reduces to (6), which is the least squares collocation model for the prediction of signals and filtering of errors without determination of parameters.

$$
l=S+V
$$

Consequently, (3) and (5) reduce to (7) and (8) respectively.

$$
\begin{aligned}
& S=C_{s l} C_{l l}^{-1} l \\
& V=C_{V V} C_{l l}^{-1} l
\end{aligned}
$$

While $\underset{-s s}{C}=C_{s s}-C_{s l} C_{l l}^{-1} C_{s l}^{T} \quad$ (error covariance matrix of signals)

From the above, it can be seen that the covariance function plays a significant role in the concept of least squares collocation technique. Basically, covariance function supplies information on the structure of the gravity field. Therefore, it should be appropriately designed to achieve the objective of least squares collocation technique. Schwarz (1976a) and Moritz (1978) suggested that it should be simple, analytical, isotropic and homogeneous. Isotropic and homogeneous requirements imply that it should be invariant with respect to rotation and translation. Also, it was stated that the matrix formed from such covariance functions must be positive definite. Positive definiteness of a non-singular symmetric matrix is achieved if the eigen values of the matrix are positive. Such matrix has dominant diagonal elements.

There are various mathematical expressions for a covariance function that represent global features of the earth. Detailed discussions on these can be found in Schwarz (1976a), Moritz (1978), Rapp (1986) and Ezeigbo (1988). However, for some limited purposes such as prediction of gravity anomalies, one may approximate the curved surface of the earth locally by a plane surface to find expressions for covariance functions that represent local features. This can functionally be given by (9) as in Moritz (1978):

$$
C(r)=C(o) /\left(1+(r / a)^{2}\right)^{1 / 2}
$$

Where: $\quad r=$ distance between two points.

$$
\begin{aligned}
& C(o)=\text { covariance function when } r=0 \\
& a=\quad \text { correlation length }
\end{aligned}
$$

Three parameters ( $C(o)$, ' $a$ ' and $r$ ) are needed, in (9) to evaluate $C(r)$. The value of $r$ is considered known, since it can be measured or computed from the given 
FUTY Journal of the Environment, Vol. I No.1, July 2006

(c) School of Environmental Sciences, Federal University of Technology, Yola - Nigeria.. ISSN 1597-8826

coordinates of gravity stations. However, the values of $C(o)$ and 'a' are unknown hence they have to be estimated. This can be achieved using an optimization technique which is a process of obtaining the optimal values of some parameters. The process is regarded successful if the estimated parameters satisfy as close as possible the objective function designed for such process. In other words, given the objective function, an optimization procedure systematically searches, among the range of possible values of parameters, and selects the best-fit values, which satisfy the given objective function. In this study, an optimisation technique is used to determine the optimal values of $C(o)$ and ' $a$ ' for the evaluation of $C(r)$ using (10) as the objective function used in Fajemirokun and Orupabo (1987).

$$
R^{2}=\left(F_{0}^{2}-F^{2}\right) / F_{0}^{2}
$$

Where: $F_{0}^{2}=\sum_{i=1}^{n}\left(\Delta g_{i}-\Delta g\right)^{2}$

$$
F^{2}=\sum_{i=1}^{n}\left(\Delta g_{i}-\Delta g_{p}\right)^{2}
$$

$\Delta g_{i}=$ observed gravity anomaly at point $\mathrm{i}$.

$\Delta g_{p}=$ predicted gravity anomaly at observation point $\mathrm{i}$.

$\Delta g=$ mean gravity anomaly

The optimisation process starts by using least squares technique to solve (11) to obtain the values of residual observations $\left(\mathrm{v}_{\mathrm{i}}\right)$.

$$
\Delta g_{i}=\Delta g_{p}+\mathrm{vi}_{\mathrm{i}}
$$

Thereafter, the initial estimates of $C(o)$ and ' $a$ ' are determined by solving (12) given by Moritz (1978).

$$
\left(\sum_{i=1}^{n-k} v_{i} v_{i+k}\right) / d f=C(o) /\left(1+(r / a)^{2}\right)^{1 / 2}
$$

Where: $d f=$ degree of freedom $=\mathrm{n}-\mathrm{m}$

$\mathrm{m}=$ number of parameters needed to represent $\Delta g_{p}$ in (11)

$\mathrm{n}=$ number of observations

$k=0,1,2$, n-1

The results are given as:

$$
\begin{aligned}
C(o) & =\sum_{i=1}^{n} v_{i} v_{i} / d f \\
a_{i} & =\left(r^{2} /\left(\left(C(o) / \sum_{i=1}^{n-k} v_{i} v_{i+k}\right)^{2}-1\right)\right)^{1 / 2} \\
a & =\sum_{i=1}^{n} a_{i} / n
\end{aligned}
$$

The final values of $C(o)$ and ' $a$ ' are obtained by systematically varying their initial values until (10)) is satisfied. The use of (10), as the condition to be satisfied, for the determination of optimum covariance parameters during the prediction of gravity anomalies at the observation stations, is logical. This is because observed gravity anomalies of the observation stations are available. However, where gravity anomalies are being predicted outside the observation stations, the initial values of the covariance parameters can be computed using the above procedure while the final values of the parameters may be obtained by systematically varying their initial values until the trace of the error covariance matrix of the predicted gravity anomalies is 
FUTY Journal of the Environment, Vol. 1 No.1, July 2006

(c) School of Environmental Sciences, Federal University of Technology, Yola - Nigeria.. ISSN 1597-8826

minimum. The trace of a square matrix is the sum of the diagonal elements of such matrix.

\section{NUMERICAL INVESTIGATIONS}

The mathematical formulations for the prediction of gravity anomalies have been discussed. Here, numerical investigations are carried out to determine the adequacy or otherwise of these formulations. The investigations include the determination of optimum covariance parameters and prediction of gravity anomalies at the observation stations. This is in addition to the separate determination of optimum covariance parameters and prediction of gravity anomalies at other stations using observed gravity anomalies of observation stations.

Determination of optimum covariance parameters and prediction of gravity anomalies at the observation stations

The process involves two stages:

(i) The values of $\Delta g_{p}$ are represented by a third order polynomial function (16).

$$
\Delta g_{p}=\mathrm{b}_{\mathrm{o}}+\mathrm{b}_{1} \mathrm{~g}_{\mathrm{i}}+\mathrm{b}_{2} \mathrm{~g}_{\mathrm{i}}{ }^{2}+\mathrm{b}_{3} \mathrm{~g}_{\mathrm{i}}{ }^{3}
$$

Where: $\quad g_{i}=$ gravity values at point $\mathrm{i}$

$\mathrm{b}_{\mathrm{o}}, \mathrm{b}_{1}, \mathrm{~b}_{2}, \mathrm{~b}_{3}=$ constant coefficients

Putting these values of $\Delta g_{p}$ in (11), the values of $\mathrm{v}_{\mathrm{i}}$ are solved for.

The values of $v_{i}$ are then used in (12), (13), (14) and (15) to obtain the initial values of covariance parameters $C(o)$ and ' $a$ '.

(ii) The parameters obtained are used in (9) to evaluate the covariance function needed

for the least squares collocation prediction of $\Delta g_{p}$ at the observation stations. The predicted gravity anomalies are functionally given as:

$$
\Delta g_{p}=C_{s l} C_{l l}^{-1} \Delta g
$$

The predicted gravity anomalies are then used in (10) to compute the value of $F_{i}^{2}$.

Thereafter, the values of the covariance parameters are allowed to vary and then used in (10) to compute the value of $F_{i+1}^{2}$. For a successful process, $F_{i+1}^{2}$ must be less than $F_{i}^{2}$. This is an iterative process, which continues until $F_{i+1}^{2}$ is minimum. (10) is satisfied when $F_{i+1}^{2}$ is minimum and $R^{2}$ is approximately equal to 1 .

\section{Determination of optimum covariance parameters and prediction of gravity anomalies at other stations}

The covariance parameters obtained, in 3.1(i) above, are used in (9) to evaluate the covariance function required for the least squares collocation prediction of gravity anomalies of other stations using observed gravity anomalies of observation stations. Using (17), the predicted gravity anomalies $\left(\Delta g_{p}\right)$ are next calculated. Then, the trace $\left(\mathrm{Tr}_{\mathrm{i}}\right)$ of the error covariance matrix of the predicted gravity anomalies is computed. 
FUTY Journal of the Environment, Vol. I No.1, July 2006

(c) School of Environmental Sciences, Federal University of Technology, Yola - Nigeria.. ISSN 1597-8826

Thereafter, the values of the covariance parameters are allowed to vary and then used to compute another trace $\left(\operatorname{Tr}_{i+1}\right)$. For a successful process, $\operatorname{Tr}_{i+1}$ must be less than $\operatorname{Tr}_{i}$. This is an iterative process, which continues until $\mathrm{Tr}_{\mathrm{i}+1}$ is minimum.

Computer programs written in Fortran 77 language are used for all the computations. The results obtained are presented below:

\section{PRESENTATION OF RESULTS}

Extract of the searched covariance parameters used for the prediction of gravity anomalies at observation stations are shown in Table 3. Row 5 of this table shows the optimum values of the parameters. The results of gravity anomaly prediction at the observation stations using classical least squares and least squares collocation techniques are shown in table 4. These include gravity station numbers, observed gravity anomalies $(\Delta \mathrm{g})$, predicted gravity anomalies using classical least squares technique $\left(\Delta \mathrm{g}_{\mathrm{ls}}\right)$, predicted gravity anomalies using least squares collocation technique $\left(\Delta \mathrm{g}_{\mathrm{col}}\right)$, difference between the observed gravity anomalies and predicted gravity anomalies of classical least squares technique ( $\left.\mathrm{v}_{\mathrm{ls}}\right)$ and difference between observed gravity anomalies and the predicted gravity anomalies by least squares collocation technique $\left(\mathrm{v}_{\mathrm{col}}\right)$.

Extract of the searched covariance parameters and traces used for the prediction of gravity anomalies outside the observation stations are shown in Table 5. Row 7 of this table shows the optimum values of the parameters with the minimum value of the trace. The error covariance matrix, which produced the minimum trace, is shown in table 6 . The results of gravity anomaly prediction for these stations using least squares collocation technique are shown in table 7 . These include gravity station numbers, observed gravity anomalies $(\Delta \mathrm{g})$, predicted gravity anomalies $\left(\Delta \mathrm{g}_{\mathrm{p}}\right)$ using least squares collocation technique and the differences between the observed gravity anomalies and predicted gravity anomalies (E). The parameters used for the statistical analysis of the results are shown in table 8 . These are degree of freedom, upper limit of table statistic, computed statistic, lower limit of table statistic and trace of error covariance matrix respectively.

Table 3: Covariance parameters for prediction at observation stations

\begin{tabular}{cccc}
$\mathrm{C}(\mathrm{o})\left(\mathrm{mGal}^{2}\right)$ & $\mathrm{a}(\mathrm{m})$ & $\mathrm{F}^{2}\left(\mathrm{mGal}^{2}\right)$ & $\mathrm{R}^{2}$ \\
\hline 2356.343089 & 1012.081477 & 0.000000000008403 & 1.000000000000 \\
2359.343089 & 1016.081477 & 0.000000000008400 & 1.000000000000 \\
2362.343089 & 1020.081477 & 0.000000000008398 & 1.000000000000 \\
2365.343089 & 1024.081477 & 0.000000000008397 & 1.000000000000 \\
2368.343089 & 1028.081477 & 0.000000000008396 & 1.000000000000 \\
2371.343089 & 1032.081477 & 0.000000000008397 & 1.000000000000 \\
2374.343089 & 1036.081477 & 0.000000000008398 & 1.000000000000 \\
\hline
\end{tabular}


FUTY Journal of the Environment, Vol. 1 No.1, July 2006

(c) School of Environmental Sciences, Federal University of Technology, Yola - Nigeria.. ISSN 1597-8826

Table 4: Comparison of predicted gravity anomalies by classical least squares and least squares collocation techniques at observation stations

\begin{tabular}{|c|c|c|c|c|c|}
\hline 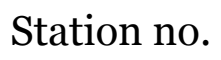 & $\Delta \mathrm{g}($ & $\Delta$ & 2 & $\mathrm{~V}_{\mathrm{ls}}(\mathrm{r}$ & $\mathrm{v}_{\mathrm{col}}(\mathrm{m}$ \\
\hline D0301040 & -31.928500 & -32.162973 & -31.928498 & -0.234473 & -0.000002 \\
\hline D0301060 & -31.772200 & -31.970325 & -31.772200 & -0.198125 & 0.000000 \\
\hline D0301100 & -31.178600 & -30.727544 & -31.178599 & 0.451056 & -0.000001 \\
\hline D0301120 & -30.773000 & -30.224369 & -30.773000 & 0.548631 & -0.000000 \\
\hline D0301160 & -30.350500 & -29.819916 & -30.350499 & 0.530585 & -0.000001 \\
\hline D0301200 & -29.833000 & -29.892698 & -29.833000 & -0.059698 & -0.000000 \\
\hline D0301220 & -29.736200 & -29.946280 & -29.736200 & -0.210080 & -0.000000 \\
\hline D0301260 & -29.421700 & -29.531857 & -29.421700 & -0.110157 & -0.000000 \\
\hline D0301300 & -29.262800 & -29.469082 & -29.262800 & -0.206282 & -0.000001 \\
\hline D0301318 & -29.038700 & -29.523856 & -29.038700 & -0.485156 & 0.000000 \\
\hline D0301346 & -29.010000 & -29.651968 & -29.010000 & -0.641969 & -0.000000 \\
\hline D0301381 & -28.987000 & -29.869728 & -28.987000 & -0.882728 & -0.000000 \\
\hline D0301420 & -29.231300 & -29.863871 & -29.231300 & -0.632571 & -0.000000 \\
\hline D0301460 & -29.609300 & -29.935659 & -29.609300 & -0.326359 & -0.000001 \\
\hline D0301480 & -29.665300 & -30.044471 & -29.665300 & -0.379171 & 0.000000 \\
\hline D0301500 & -29.897100 & -30.145885 & -29.897100 & -0.248785 & -0.000001 \\
\hline D0301540 & -30.442700 & -30.183086 & -30.442699 & 0.259614 & -0.000001 \\
\hline D0301580 & -30.579400 & -30.255215 & -30.579400 & 0.324185 & -0.000000 \\
\hline D0301620 & -31.330000 & -30.150072 & -31.329999 & 1.179928 & -0.000001 \\
\hline D0301638 & -31.223900 & -30.213197 & -31.223900 & 1.010703 & 0.000000 \\
\hline D0301660 & -31.096500 & -30.355059 & -31.096500 & 0.741441 & -0.000000 \\
\hline D0301700 & -30.958100 & -30.338371 & -30.958099 & 0.619729 & -0.000001 \\
\hline D0301720 & -30.586200 & -30.252909 & -30.586200 & 0.333291 & 0.000000 \\
\hline D0301740 & -30.112100 & -30.023778 & -30.112100 & 0.088322 & -0.000001 \\
\hline D0301780 & -29.173300 & -29.462521 & -29.173300 & -0.289221 & -0.000000 \\
\hline D0301800 & -28.809800 & -29.338324 & -28.809800 & -0.528524 & -0.000001 \\
\hline D0301840 & -27.492100 & -28.356779 & -27.492100 & -0.864679 & -0.000000 \\
\hline D0301860 & -26.900200 & -27.355042 & -26.900200 & -0.454842 & -0.000000 \\
\hline D0301880 & -26.256800 & -26.646990 & -26.256800 & -0.390190 & 0.000000 \\
\hline D0301920 & -25.579700 & -24.524175 & -25.579699 & 1.055526 & -0.000001 \\
\hline
\end{tabular}

Table 5: Covariance parameters and trace for prediction outside the observation stations

\begin{tabular}{ccc}
$\mathrm{C}(\mathrm{o})\left(\mathrm{mGal}^{2}\right)$ & $\mathrm{a}(\mathrm{m})$ & $\mathrm{Tr}\left(\mathrm{mGal}^{2}\right)$ \\
\hline 32.3430862 & 1565.0814209 & 1.7523 \\
27.3430862 & 1570.0814209 & 1.4520 \\
22.3430862 & 1575.0814209 & 1.1633 \\
17.3430862 & 1580.0814209 & 0.8858 \\
12.3430862 & 1585.0814209 & 0.6192 \\
7.3430862 & 1590.0814209 & 0.3630 \\
2.3430862 & 1595.0814209 & 0.1171 \\
-2.6569138 & 1600.0814209 & 145.8184 \\
\hline
\end{tabular}


FUTY Journal of the Environment, Vol. 1 No.1, July 2006

(c) School of Environmental Sciences, Federal University of Technology, Yola - Nigeria.. ISSN 1597-8826

Table 6: Error covariance matrix of predicted gravity anomalies $\left(\mathrm{mGal}^{2}\right)$

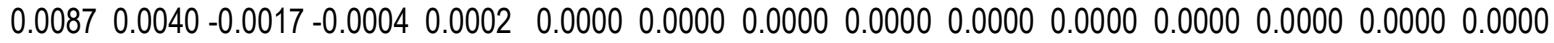
$\begin{array}{llllllllllllllll}0.0040 & 0.0095 & -0.0063 & -0.0018 & 0.0007 & 0.0001 & -0.0001 & 0.0000 & 0.0000 & 0.0000 & 0.0000 & 0.0000 & 0.0000 & 0.0000 & 0.0000\end{array}$

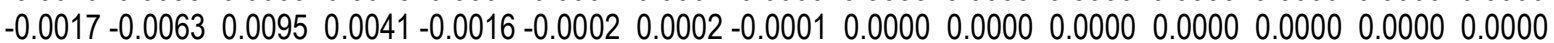

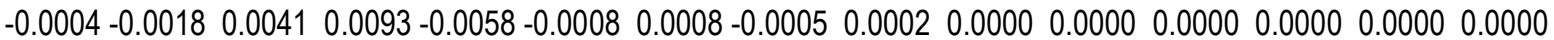
$\begin{array}{llllllllllllllll}0.0002 & 0.0007 & -0.0016 & -0.0058 & 0.0081 & 0.0017 & -0.0018 & 0.0011 & -0.0004 & 0.0001 & 0.0000 & 0.0000 & 0.0000 & 0.0000 & 0.0000\end{array}$ $\begin{array}{lllllllllllllll}0.0000 & 0.0001 & -0.0002 & -0.0008 & 0.0017 & 0.0018 & -0.0023 & 0.0017 & -0.0006 & 0.0001 & 0.0000 & 0.0000 & 0.0000 & 0.0000 & 0.0000\end{array}$

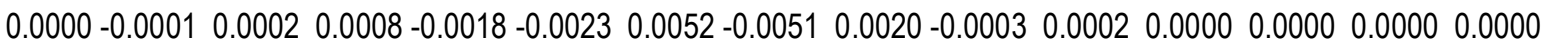

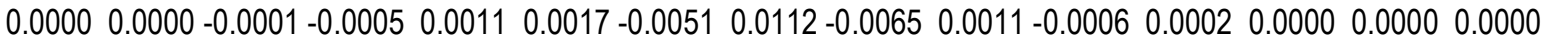

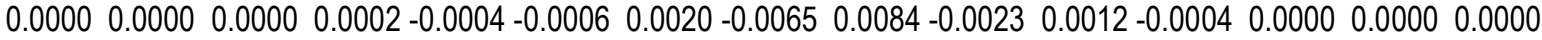

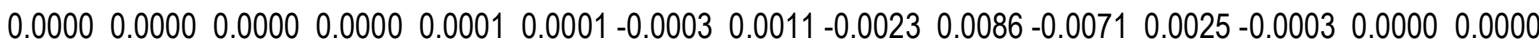

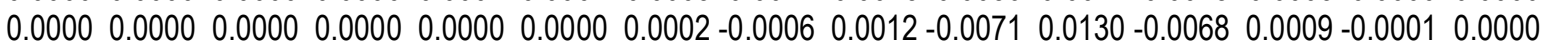

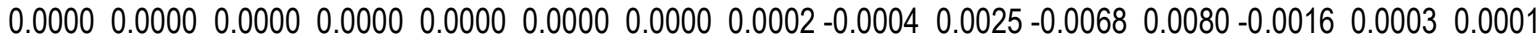

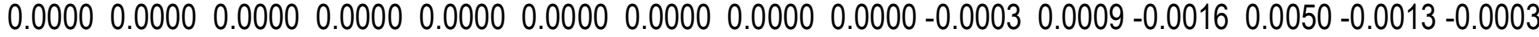

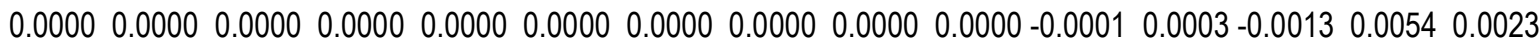
$\begin{array}{lllllllllllllllll}0.0000 & 0.0000 & 0.0000 & 0.0000 & 0.0000 & 0.0000 & 0.0000 & 0.0000 & 0.0000 & 0.0000 & 0.0000 & 0.0001 & 0.0003 & 0.0023 & 0.0055\end{array}$

Table 7: Predicted gravity anomalies outside the observation stations by least squares collocation

\begin{tabular}{cccc}
\hline Station no. & $\Delta \mathrm{g}(\mathrm{mGal})$ & $\Delta \mathrm{g}_{\mathrm{p}}(\mathrm{mGal})$ & $\mathrm{E}(\mathrm{mGal})$ \\
\hline D0301080 & -31.482100 & -31.495761 & 0.013661 \\
$\mathrm{D} 0301140$ & -30.585700 & -30.515984 & -0.069716 \\
D0301180 & -29.958800 & -30.064126 & 0.105326 \\
D0301240 & -29.578400 & -29.571339 & -0.007061 \\
D0301280 & -29.177600 & -29.395232 & 0.217632 \\
D0301334 & -29.024300 & -28.977007 & -0.047293 \\
D0301360 & -29.070900 & -29.029677 & -0.041223 \\
D0301400 & -29.197900 & -29.027411 & -0.170489 \\
D0301440 & -29.462800 & -29.480838 & 0.018038 \\
D0301520 & -30.141500 & -30.250076 & 0.108576 \\
D0301560 & -30.588100 & -30.428336 & -0.159764 \\
D0301600 & -30.817100 & -31.041928 & 0.224828 \\
D0301680 & -31.218200 & -31.102384 & -0.115816 \\
D0301760 & -29.729900 & -29.579175 & -0.150725 \\
D0301820 & -28.225200 & -28.166052 & -0.059148 \\
\hline
\end{tabular}

Table 8: Trace, computed and table statistics at $\alpha=0.05$

\begin{tabular}{ll}
\hline Degree of freedom & 15 \\
Table statistic (Upper limit) & 27.49 \\
Computed statistic & 10.0281 \\
Table statistic (Lower limit) & 6.26 \\
Trace & 0.1171 \\
\hline
\end{tabular}


FUTY Journal of the Environment, Vol. 1 No.1, July 2006

(c) School of Environmental Sciences, Federal University of Technology, Yola - Nigeria.. ISSN 1597-8826

\section{ANALYSIS OF RESULTS}

As shown in table 4, it can be seen that the predicted gravity anomalies of least squares collocation are better than those of classical least squares. This appears to confirm the supremacy of the least squares collocation technique over the classical least squares technique. In table 7 , the predicted gravity anomalies of other stations compare favourably well with the "true" gravity anomalies for these stations. This tends to indicate a satisfactory level of reliability of the predicted anomalies outside the observation stations.

Statistical investigation is carried out to test the reliability of the predicted gravity anomalies obtained for the other stations (outside the observation stations). This is to show that the procedure used for the prediction has (or has not) introduced distortions in the predicted values. In order words, $\mathrm{E}^{\mathrm{T}} \mathrm{C}_{\mathrm{ss}^{-1}} \mathrm{E}$ is statistically examined to know whether it falls within the specified confidence limits or not. This is achieved by means of Chi-Squares $\left(\chi^{2}\right)$ test. That is, we test the hypothesis:

Null hypothesis: $\quad \mathrm{H}_{\mathrm{o}}: \mathrm{E}^{\mathrm{T}} \mathrm{C}_{\mathrm{ss}}{ }^{-1} \mathrm{E}=\sigma_{0}{ }^{2} \quad\left(\mathrm{E}^{\mathrm{T}} \mathrm{C}_{\mathrm{ss}}{ }^{-1} \mathrm{E}\right.$ is within the confidence limits) Alternative hypothesis: $\mathrm{H}_{1}: \mathrm{E}^{\mathrm{T}} \mathrm{C}_{\mathrm{ss}^{-1}} \mathrm{E} \neq \sigma_{0}{ }^{2} \quad\left(\mathrm{E}^{\mathrm{T}} \mathrm{C}_{\mathrm{ss}}{ }^{-1} \mathrm{E}\right.$ is outside the confidence limits)

Where $\mathrm{E}^{\mathrm{T}} \mathrm{C}_{\mathrm{ss}}{ }^{-1} \mathrm{E} / \sigma_{\mathrm{o}}{ }^{2}$ is the computed statistic $\left(\chi^{2}\right)$.

This is a two-tail test where the Null Hypothesis is rejected if the computed statistic is outside the confidence limits. The confidence limits are the upper limit and the lower limit of the table statistic. They are obtained in the statistical table as $\chi^{2}{ }_{1-\alpha / 2, d f}$

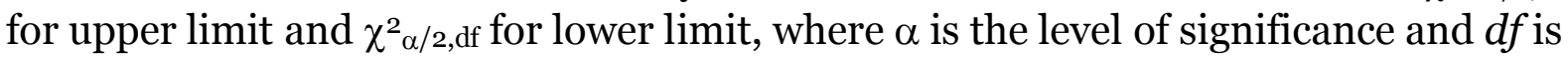
the degree of freedom (number of observations (n) minus number of predicted gravity anomalies outside the observation stations (u)). From table 8, it can be seen that the value of computed statistic falls within the confidence limits. This suggests that the null hypothesis, that $\mathrm{E}^{\mathrm{T}} \mathrm{C}_{\mathrm{ss}^{-1}}{ }^{-1} \mathrm{E}$ is within the confidence limit, should not be rejected. Therefore, it can be inferred that the technique used for the prediction has not introduced distortion in the values of the predicted gravity anomalies.

Also, the values of $\mathrm{E}$ are examined, using statistical t-distribution, to know whether or not they fall within the tolerant error limit (e) for the predicted quantities. The tolerance error limit (e) is defined by (18) and (19) as in Ayeni (2001).

$$
\begin{aligned}
& \mathrm{e}= \pm \sigma \mathrm{t}_{\mathrm{u}-1,1-\alpha / 2} / \mathrm{u}^{1 / 2} \\
& \sigma=\left(\mathrm{E}^{\mathrm{T}} \mathrm{C}_{\mathrm{ss}^{-1}} \mathrm{E} /(\mathrm{u}-1)\right)^{1 / 2}
\end{aligned}
$$

From the statistical table, also in Ayeni (2001), $t_{\mathrm{u}-1,1-\alpha / 2}=2.145$. The computed value of $\sigma=0.846$. Hence, the value of $\mathrm{e}= \pm 0.4687$. It can be seen, from table 7 , that all the values of $\mathrm{E}$ fall within the tolerant error limit (e) thereby confirming the high level of reliability of the predicted gravity anomalies for geophysical exploration.

\section{CONCLUSIONS AND RECOMMENDATIONS}

An attempt has been made to predict gravity anomalies, using least squares collocation technique, for geophysical exploration. When compared with the classical least squares method in the prediction of gravity anomalies, the least squares collocation technique gave the better results. The accurate choice of covariance parameters for the design of covariance functions has helped to ensure the high level of reliability of the predicted gravity anomalies. The predicted gravity anomalies have been found to be reliable at the significance level of 0.05. Therefore, prediction of 
FUTY Journal of the Environment, Vol. I No.1, July 2006

(c) School of Environmental Sciences, Federal University of Technology, Yola - Nigeria.. ISSN 1597-8826

gravity anomalies is recommended to improve the density distribution of the observed gravity anomalies of points in a survey area for geophysical exploration.

\section{REFERENCES}

Abdelrahman, E. M., Bayoumi, A. I. and El-Araby, H. M. (1991): A least squares minimization approach to invert gravity data. Journal of Geophysics, Vol. 56 No. 28, pp.115-118.

Ayeni, O. O. (2001): Statistical Adjustment and Analysis of Data. Lecture note series, Department of Surveying and Geoinformatics, University of Lagos, Nigeria.

Ezeigbo, C. U. (1988): Least squares collocation method of geoid and datum determination for Nigeria. Ph.D. Thesis, Department of Surveying, University of Lagos, Nigeria.

Fajemirokun, F. A. and Orupabo S. (1987): Computation of residual anomalies for south-eastern, Nigeria. International Workshop on the stability of the Western Sector of African Plate, University of Ibadan, Nigeria.

Gumert, W. R. (1992): Airborne gravity measurements, in CRC Handbook of Geophysical Exploration at Sea, $2^{\text {nd }}$ edition, CRC Press.

Kearey, P. and Brooks, M. (1988): An Introduction to Geophysical Exploration. The Garden City, Blackwell Scientific Press, Letchworth, Herts.

Krakiwsky, E. J. (1975): Recent Advances in least squares: Lecture Note Series. University of News-Brunswich, Canada.

Moritz, H. (1972): Advanced least squares method. Report No. 175, Department of Geodetic Science, The Ohio State University.

Moritz, H. (1978): Least squares collocation. Journal of American Geophysical Union, Vol. 16, pp. 201-205.

Osazuwa, I. B. (1995): Nigeria gravity network project: achievements and challenges. Proceedings of the second Regional Geodesy and Geophysics Assembly in Africa. Pp.16-25.

Rapp, R.H. (1986): Global Geopotential Solutions. Lecture Notes in Earth Sciences. Department of Geodetic Sciences and Surveying, Ohio State University.

Reynolds, J.M. (1998): An Introduction to applied and environmental geophysics. Published by John Wiley \& Sons ltd. West Sussex, England.

Schwarz, K.P. (1976): Least Squares Collocation for large systems. Boll. Geod. Scl. Affini. Vol. 35, pp.309-324.

Senti, R. J. (1988): Geophysical activity in 1987. Journal of geophysics: The leading edge of exploration. Vol. 7, pp.33-56.

SNEPCO (1995): Final Report of Gravity Survey on Gongola Basin of Nigeria. Lagos, Nigeria. 